\title{
Power Electronics - Key Technology for Renewable Energy Systems - Status and Future
}

\author{
Frede Blaabjerg, Yongheng Yang, Ke Ma \\ Center of Reliable Power Electronics, Department of Energy Technology \\ Aalborg University \\ Pontoppidanstraede 101, Aalborg DK-9220, Denmark \\ fbl@et.aau.dk, yoy@et.aau.dk, kema@et.aau.dk
}

\begin{abstract}
The energy paradigms in many countries (e.g. Germany and Denmark) have experienced a significant change from fossil-based resources to clean renewables in the past few decades. The scenario of highly penetrated renewables is going to be further enhanced. This requires that the production, distribution and use of the energy should be as technological efficient as possible and incentives to save energy at the end-user should also be streng-thened. In order to realize the transition smoothly and effectively, energy conversion systems, currently based on power electronics technology, will again play an essential role. Using highly efficient power electronics in power generation, power transmission/ distribution and end-user application, together with advanced control solutions, can pave the way for renewable energies. In view of this, some of the most emerging renewable energies, e.g. wind energy and photovoltaic, which by means of power electronics are changing character as a major part in the electricity generation, are explored in this paper. Issues like technology development, implementation, power converter technologies, control of the systems, and synchronization are addressed. Special focuses are paid on the future trends in power electronics for those systems.
\end{abstract}

Keywords - power electronics; renewable energy systems; photovoltaic systems; wind turbine systems; reliability; advanced control; ancillary services

\section{INTRODUCTION}

With an imperative demand of reliable and environmentally friendly electricity generation from Renewable Energy Systems (RESs), the total power generation of RESs is continuously booming and is going to be tripled within the next few decade [1]-[4]. Consequently, great efforts have been made by many countries (e.g. Germany, Spain, and Denmark) to introduce more renewable energies such as wind power, PhotoVoltaic (PV) power, hydropower, and biomass power, etc. to be integrated into the electric grid. As it is shown in Fig. 1, among various renewable energies, Wind Turbine System (WTS) and PV system technologies are still the most promising technologies, accounting for a large portion of renewable energy generation [4]-[14]. However, the increasing adoption of RESs poses two major challenges, which are in urgent need to be coped with. One is the change of electrical power production from the conventional and fossil-based energy sources to renewable energy resources. The other one is the wide-scale use of power electronics in the power generation, the power transmission/ distribution and the end-user application.

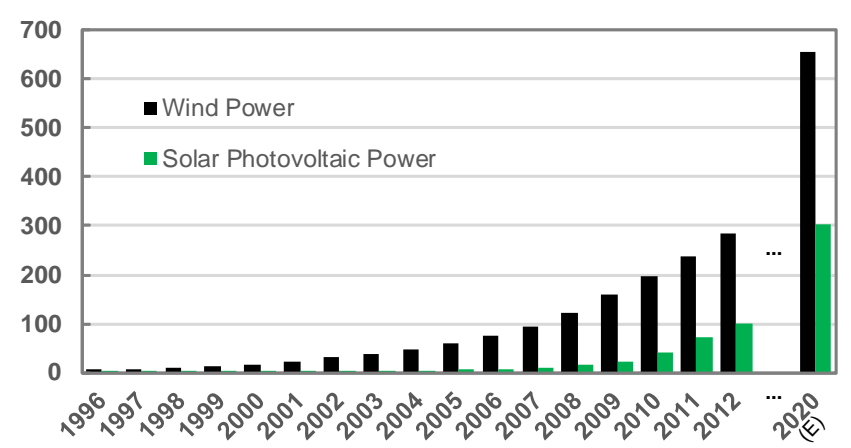

Fig. 1. Global cumulated wind power and solar photovoltaic capacity (Gigawatts) from 1996 to 2012, and an Estimation (E) by 2020 [1], [2].

The power electronics systems should be highly efficient and exceedingly reliable. As this technology has been the key to the energy conversion from the most emerging renewable energy sources, e.g. WTS and PV systems, it should be able to transfer the renewable energies to the power grid, and capable to exhibit advanced ancillary functions (e.g. Low Voltage Ride-Through, LVRT, grid support with reactive power injection). A wide-scale adoption of power electronics technology makes those completely weather-based energies more controllable, but increasingly intricate. Underpinned by intelligent control strategies, the power electronics technology can fulfill the requirements imposed by the distribution/ transmission system operators as well as specific demands from the end-customers, especially when more advanced power devices and more accurate knowledge of the mission profiles are available.

In this paper, the status and the future trends in power electronics technology, which enables a clean and reliable power conversion from WTSs and PV systems, are discussed. In Section II, the basic demands of RESs are firstly presented, and followed by the WTS and PV technologies including main power converter topologies for both PV systems and WTSs. Then, typical control strategies for PV systems and wind turbines are presented by considering the grid demands. Due to the increasing complexity of the future power systems integrated with a large amount of RESs, in Section III, the focuses are paid on the trends in power electronics technology as the key to renewable energy integration. Finally, the conclusions and perspectives are given for the two main renewable energies. 


\section{POWER ELECTRONICS FOR RESS}

\section{A. Demands of Renewable Energy Systems}

Fig. 2 demonstrates the architecture of a modern RES based power generation system, where the power electronics unit is the core of the system. An increasing penetration level of RESs results in more stringent grid demands. As it is shown in Fig. 2, the tasks of a power electronics based RES are as varied as they are demanding by the local operators or the end-customers [4], [5]. A very common demand of a RES is to transfer the energy to the grid based on the renewable energy characteristics. Other specific demands can be summarized as: a) reliable/secure power supply, b) high efficiency, low cost, small volume, and effective protection, c) control of active and reactive power injected into the grid, d) dynamic grid support (ride-through operation), and e) system monitoring and communication.

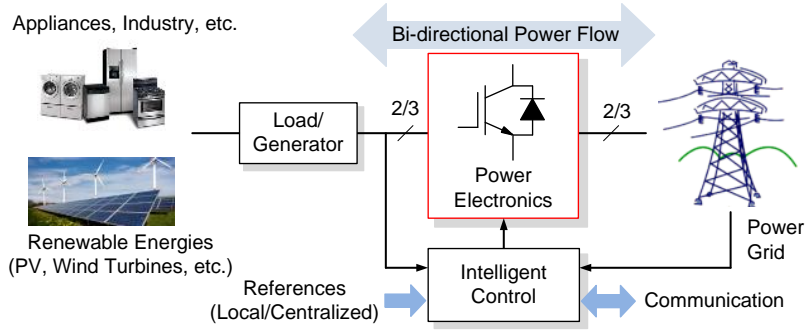

Fig. 2. Advanced modern power electronics technologies and intelligent control techniques for renewable energy sources and loads.

\section{B. RES Technologies and Power Converter Topologies}

The design and operation of power electronics converters for both wind turbine and PV systems strongly rely on the grid requirements and the energy demand. It can be seen from the evolution of wind turbine power converters, which has changed from non-power-electronics-based topologies to full-scale power converters with increasing power ratings of individual wind turbine (tens-kW to several MW) [4], [8]-[10], [12]. As the demand of higher power ratings and efficiency increases for PV systems, the PV power converters also had an obvious change, and they are mostly transformerless nowadays [4], [6], [7].

For WTSs, the most commonly used design concepts can be categorized into four types: 1) fixed speed wind turbine systems, 2) partial variable speed wind turbine with variable rotor resistance, 3) variable speed wind turbine with partialscale frequency converter, and 4) variable speed wind turbine with full-scale power converter. Among those WTS configurations, the latter two types are currently dominant in the markets and they are shown in Fig. 3. Moreover, the two concepts are expected to be even more widely adopted in the future.

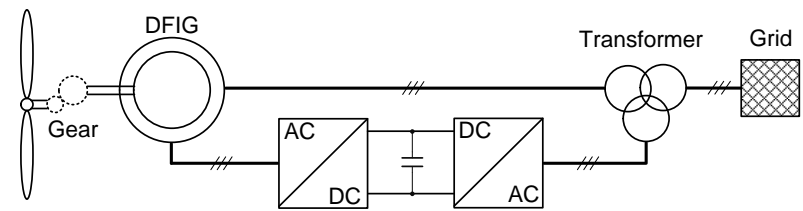

(a) Partial-scale back-to-back power converter based wind turbine system

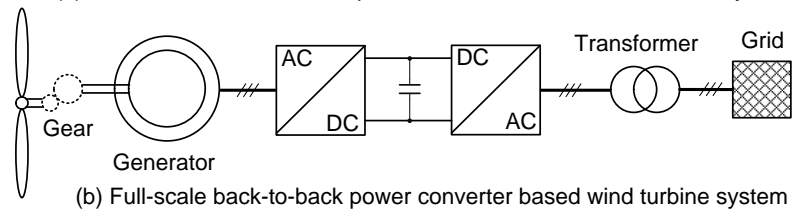

Fig. 3. Two dominant power electronics based WTS configurations.

As it is indicated in Fig. 3, the power electronics technology plays an essential role in those two concepts. Regarding the power converter topologies for wind power applications, the most commonly adopted three-phase converter is the two-level Voltage Source Converter (2L-VSC), featuring with simple structure and few components, as it is shown in Fig. 4. However, since the power capacity of an individual wind turbine keeps growing up to even $10 \mathrm{MW}$ [13], [14], the 2L-VSC is not very feasible due to lower efficiency. In view of this, the multi-level converter technology, which can achieve more output voltage levels, higher voltage and larger output power, gains much more popularity in the wind turbine applications [9], [10], [13]-[16].

The most commercialized multi-level converter is the threelevel Neutral Point diode Clamped (3L-NPC) topology shown in Fig. 5. Compared to the 2L-VSC, 3L-NPC can achieve one more output voltage level, thus leading to a smaller filter. The major drawback of this converter is the unequal loss distribution between the inner and outer switching devices, which may contribute to a de-rated converter power capacity [14], [15]. To solve this problem, multi-cell converter topologies (i.e. parallel/ series connection of converter cells) are developed and widely adopted by the industries (e.g. Gamesa and Siemens) [17], [18]

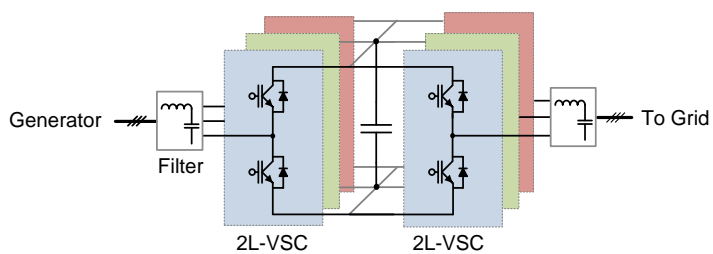

Fig. 4. 2L-VSC Back-to-Back (2L-VSC BTB) converter.

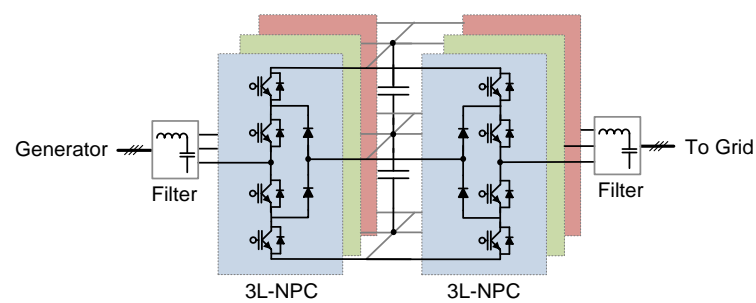

Fig. 5. 3L-NPC Back-to-Back (3L-NPC BTB) converter. 


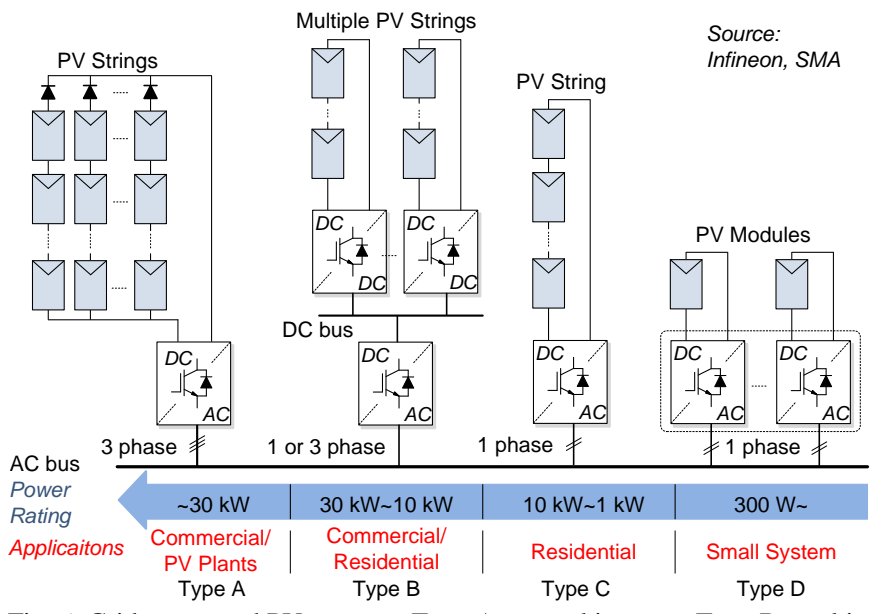

Fig. 6. Grid-connected PV systems: Type A- central inverter; Type B- multistring inverter; Type C- string inverter; Type D- module inverter [6].

For PV systems, a general classification of grid-connected PV inverters is shown in Fig. 6. A common central inverter can be used in a PV plant larger than tens $\mathrm{kWp}$ with higher efficiency and lower cost. Its major disadvantages are high voltage DC cables, common Maximum Power Point Tracking (MPPT) and module mismatch [6]. Compared to central inverters, the string inverter can achieve MPPT separately, leading to better total energy yield. However, there are mismatches in the PV panels connected in series. Thus, the module inverter is developed, which acts on a single PV panel with a single MPPT. The main disadvantage of a module inverter is the low overall efficiency. Another PV technology is an intermediate solution between the string inverter and the module inverter, being multi-string inverter. This configuration is flexible with a high overall efficiency because each PV string is controlled separately.

In contrast to WTSs, the PV systems are still dominant in residential applications with much lower power ratings (e.g. several $\mathrm{kW}$ ), as it is shown in Fig. 6. Thus, at present, singlephase topologies are more common for the PV applications. Normally, in those cases, DC/DC converters are adopted to boost up the PV voltage within an acceptable range of the PV inverter. The boost converter also offers the flexibility of extracting the maximum power. However, several PV power plants have come into service recently using central inverters (e.g. SMA Sunny Central CP XT inverter) and more are under construction, due to an intense energy demand and carbon dioxide emission reduction. The power converter technology for this is similar to the grid side converter technology in WTSs.

When it comes to the design of PV inverters as well as their related control methods, the efficiency and leakage current are two main considerations. Connecting the PV inverters to the grid through isolation transformers can solve the safety issues due to the leakage current, but leading to a lower efficiency and a more bulky system. Thus, transformerless PV inverters are developed [4], [6], [7], [19]-[25] by considering the leakage current issue and they have gained much more popularity especially in the European markets. A widely adopted singlephase PV inverter is the Full-Bridge (FB) topology as shown in Fig. 7. Two main modulation schemes are available for the FB inverter - unipolar modulation and bipolar modulation. In the light of safety issues, the FB with bipolar modulation is more feasible in single-phase transformer-less PV applications. However, the conversion efficiency is not very satisfied.

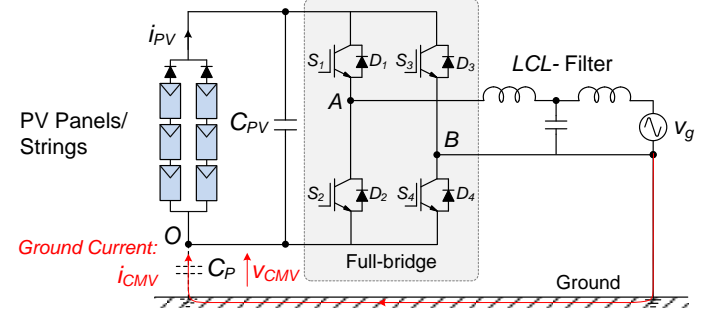

Fig. 7. Single-phase full-bridge PV inverter with an $L C L$-filter.

Many other transformerless PV inverters available on the markets are derived from the FB topology. For instance, the H6 inverter patented by Ingeteam [20] shown in Fig. 8 disconnects the PV panels/strings from the inverter using four extra devices to realize the "isolation"; while the Highly Efficient and Reliable Inverter Concept (HERIC inverter) by Sunways [22] provides an AC bypass. There have been other topologies reported in the literature, [7], [23]-[25]. An example shown in Fig. 9 is based on the Neutral Point Clamped (NPC) technology.

\section{Control of Renewable Energy Systems}

The first priority of the RES control is to extract as much energy as possible for the renewable energies in normal operation, which is known as MPPT. As the penetration level $\mathrm{O}$

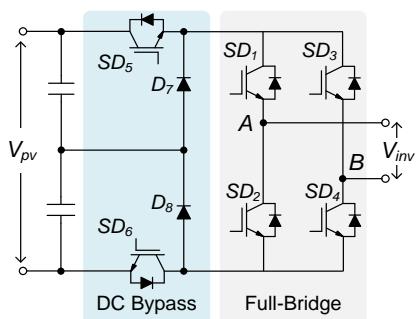

(a) $\mathrm{H} 6$ inverte

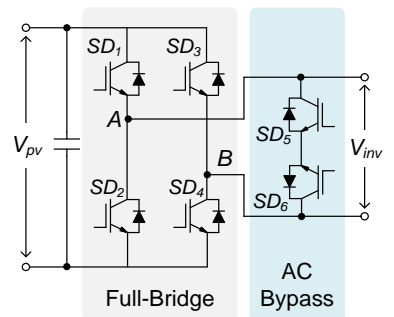

(b) HERIC inverter
Fig. 8. Two transformerless PV inverters (H6 and HERIC) [20], [22].

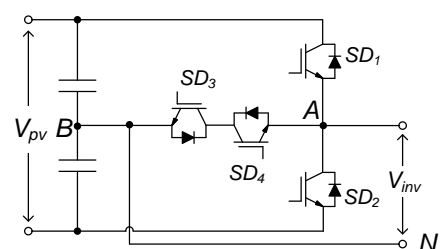

Fig. 9. Neutral point clamped transformerless topology for PV application.

RESs continues growing, many specific grid requirements have been imposed on those systems. It is further better for the RESs to provide ancillary services, such as LVRT, reactive power control and frequency control through active power control, in order to ensure a reliable and efficient power conversion from such renewable energies. For example, in Germany, the medium- and/or high-voltage systems should have LVRT capability with reactive power injection [4], [5], [10], [26], [28], and in Italy, similar requirement has been published and acted on low power rating systems $(6 \mathrm{~kW})$ [27].

Hence, it can be seen that the distribution/transmission system operators (DSO/TSO) have given priority to finding a 
solution in order to guarantee stable operation of RESs and accept more renewable energies. This consideration should be taken into account, which makes the control systems of RESs multi-functional, as shown in Fig. 10 and Fig. 11. The basic controls like current regulation, DC bus stabilization and grid synchronization have to be quickly performed by the power converter, where a Proportional-Integral (PI) controller and Proportional-Resonant (PR) controllers are typically used [5].

Some advanced control functions of RESs, e.g. riding through operation of the grid faults and providing grid-support functions, are needed for both WTSs and PV systems as shown in Fig. 10 and Fig. 11. In the variable speed wind turbine concept, the current in the generator will typically be changed by controlling the generator side converter, and thereby the rotational speed of turbine can be adjusted to achieve maximum power production based on the available wind power. In respect to operation under grid fault, coordinated control of several subsystems in the wind turbine such as the generator/grid side converters, braking chopper/ crowbar and pitch angle controller, is necessary in order to handle the situation properly.

For the reactive power injection during LVRT operation in WTS applications, there are at least four major strategies available [4], [5], [28]-[32]: 1) unity power factor control, 2) positive and negative sequence control, 3) constant active power control and 4) constant reactive power control. Unbalanced grid faults are one of the most observed faults in three-phase systems. Since there is an interaction between voltage sequences and current sequences under grid faults, either the controlled active power or the controlled reactive power will give oscillations.

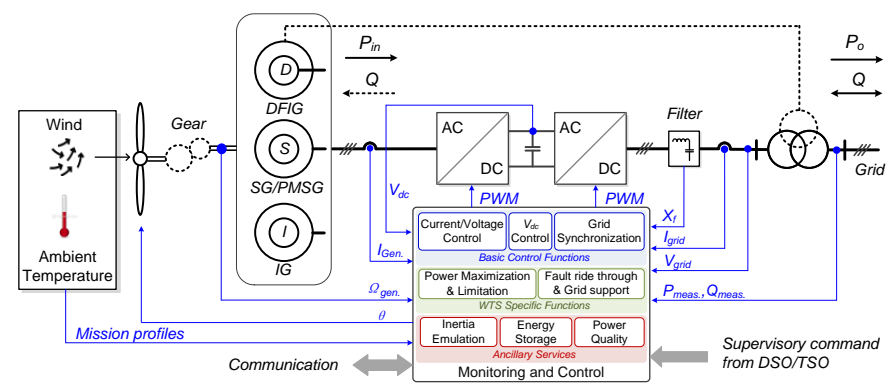

Fig. 10. General control function blocks for modern wind turbine systems.

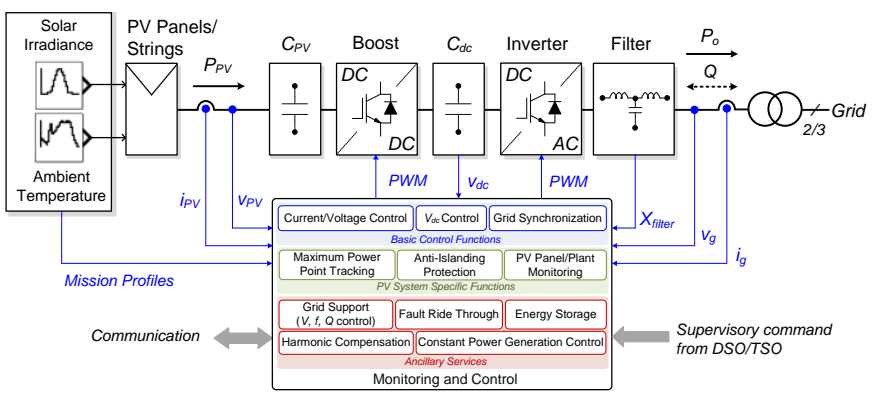

Fig. 11. General control function blocks of a typical PV system with a DC/DC boost stage.

As the PV systems are still at residential level in respect to single-phase systems, there are less control freedoms (grid voltage and grid current) under grid faults. Typically, they are required to cease energizing local loads under grid faults, known as anti-islanding protection. However, the penetration level increases the necessity of LVRT with reactive power injection [33]-[35]. By considering the over-current protection of PV inverters and the reactive current injection requirements under grid faults, possibilities for reactive power injection of single-phase PV systems can be [36]: 1) constant peak current strategy, 2) constant average active power strategy, 3) constant active current strategy, and 4) thermal optimized strategy. As for the three-phase PV systems, the control under grid faults is similar to that of the grid side converter in a wind power system, and thus the above strategies can be adopted and implemented in the different reference frames [4], [5].

\section{Synchronizations in Renewable Energy Systems}

The injected current into the grid has to be synchronized well with the grid voltage, as standards require that in the field [4]-[6]. Therefore, the grid synchronization issue plays an important role for both WTSs and PV systems. To address this problem, Phase Locked Loop (PLL) based synchronization methods stand out of various reported solutions [5]. Evaluating criterions for synchronization methods are the dynamic response speed and the disturbance rejection capability. The Second Order Generalized Integrator based PLL (SOGI-PLL) presents a better performance compared to other methods, especially for single-phase systems [4], [5]. It can be a good candidate for the synchronization for RESs and used in industrial applications.

Moreover, in respect to the aforementioned control methods for WTSs and PV systems, a fast and accurate synchronization system will strongly contribute to the dynamic performance and the stability margin of the whole control systems. The knowledge of grid conditions significantly affects the control systems in different operation modes. For example, the detection of the grid faults and the extraction of positive and negative sequence currents are of importance for the control of RESs in LVRT operation modes.

\section{FUTURE TRENDS IN POWER ELETRONICS FOR RESS}

As the heart of every renewable energy generation system, the power electronics converter is responsible for the power generation from wind and solar energy efficiently and reliably. Thus, to realize a widespread adoption of such renewables, the power electronics technology will be more active into the grid in the future. Together with advanced control strategies, it can fulfill the upcoming stringent requirements regarding the efficiency, the controllability, the cost and the reliability.

\section{A. More Power Electronics and Intelligent Control}

In the last few decades, the power electronics technology has become more and more advanced and brought significant improvements for the renewable energy generation [8]-[10], [37]- [39]. Together with intelligent control strategies, modern power electronics technology makes RESs more controllable and as active as the conventional power plants. There will more advanced power electronics systems in the future RESs in order to enable a better and flexible integration with the power grid.

For instance, it can be seen from the evolution of the wind turbine technology in Fig. 12 that the power electronics 
converter has already achieved $100 \%$ power coverage in the wind turbine system since 2005, while the PV systems have already been complete power electronics based systems. Fully power-electronics-based wind turbine technology will be further enhanced by advanced control strategies. Actually, in most of the newly established WTSs, power electronics converters have become essential components carrying all of the generated power up to multi-MW [5]-[9].

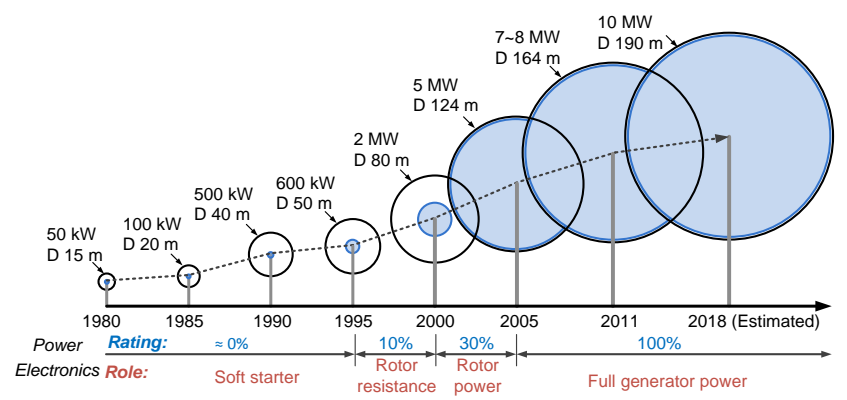

Fig. 12. Evolution of wind turbine size and the power electronics seen from 1980 to 2018 (Estimated), where the blue circle indicates the power coverage by power electronics.

\section{B. More Stringent Grid Requiements}

In order to accept more renewables in the grid, the conventional power grid, which is normally based on centralized and large power plants, have to be modified to be more distributed and smaller generation units. Thus, new demands for grid integration standards, communication, power flow control, and protection are needed [10]-[12]. Power electronic converters together with dedicated and intelligent control strategies again play an important role in this technology transformation.

Taking the PV systems as an example, typically, MPPT is required during the operation. However, recent studies showed that a limitation of the maximum feed-in power from PV systems only contributes a limited energy reduction, as it is shown in Fig. 13. Thus, it is reasonable to avoid upgrading power infrastructure by limiting the maximum feed-in power from PV systems. This may be included in the future grid demands at a very high penetration level. The same philosophy may be imposed on other renewables (e.g. fuel-cell system). In that case, the control of power electronics should be ready.

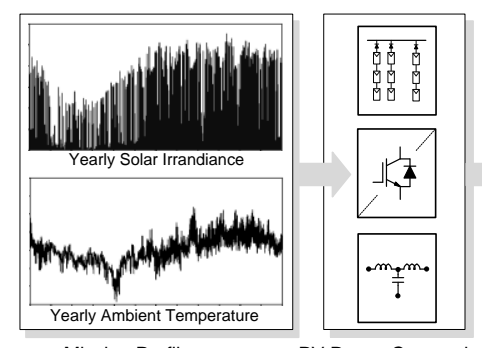

Mission Profiles

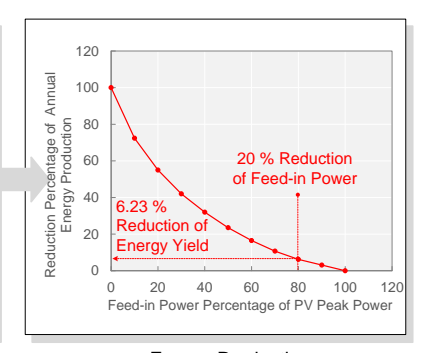

Energy Production
Fig. 13. Energy reduction due to the limitation of maximum feed-in power.

\section{Lower Cost of Energy}

Reducing the cost of energy is one of the most important considerations, which may affect the installation capacity of the energy technologies. Generally, a Levelized Cost of Energy (LCOE) index is adopted to quantify and compare the cost for different renewables [40]-[42], and it can be expressed as,

$$
L C O E=\frac{C_{D e v}+C_{C a p}+C_{O \& M}}{E_{\text {Annual }}}
$$

in which $C_{D e v}$ is the initial development cost, $C_{c a p}$ represents the capital cost, $C_{O \& M}$ denotes the cost for operation and maintenance, and $E_{\text {Annual }}$ is the average annual energy production in the whole lifetime. It is shown in (1) that the possibilities to lower the cost of energy are: a) to reduce the cost for development, capital, operation and maintenance and b) to extend the energy production or increase the lifetime of the generation system.

As it is shown in Fig. 14, the onshore wind power technology is currently competitive with the fossil-based power generation in terms of the cost, while offshore wind power and solar PV technologies are still more expensive than the onshore wind power. The cost advantage is the main contribution to the significant adoption of onshore wind power systems in the past few decades. As it is indicated in Fig. 14, there is large potential to reduce the cost of offshore wind and solar PV technologies in the future. Since the power electronics technology is the key technology for RESs with higher power ratings, special cost considerations should also be taken into account for the design and control of power electronics converters.

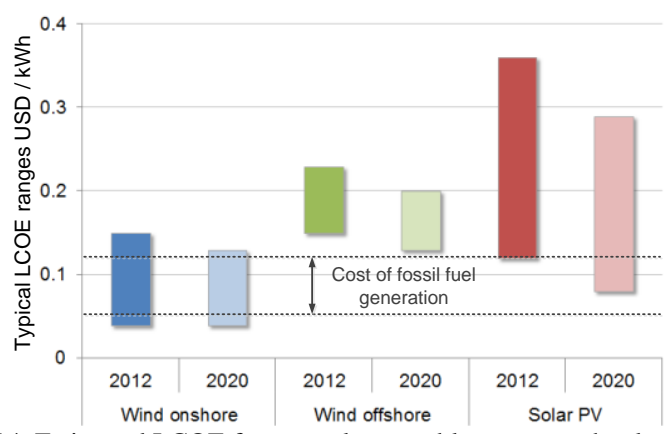

Fig. 14. Estimated LCOE for several renewable energy technologies for entering service in 2018 [41].

\section{High Efficiency and High Reliability}

Achieving high efficiency and high reliability are always of intense interest in order to reduce energy losses and to extend service time, and it will be further strengthened in the future RESs. Improvements of efficiency can be achieved by integrating more power electronics systems with intelligent control strategies and developing more advanced power electronics devices (e.g. SiC-based modules). For example, transformerless PV inverters will be even more widely adopted since they can achieve high efficiency. As the devices and components that comprise the power electronics system in a RES, the behavior of the power electronics devices will impose constraints on the system conversion performance [37]-[39]. Thus, for the future wind power systems with high power ratings, using advanced power electronics devices can improve the whole performance in terms of efficiency and reliability.

Notably, the dramatic growth of total installations and the individual capacity make the failures of wind power or PV system costly or even unacceptable. In view of this, the reliability is another critical requirement for the future RESs [9], [10], [14], [37]. According to previous research and field 
experiences, the control and power electronics systems in a RES have higher failure rate than the other subsystems. Therefore, possible improvements of the reliability can be achieved by means of: a) proper component selection (e.g. considering rated power, the most stressed situations, and the severe users, using advanced device packaging technologies, and choosing new power electronics devices), b) effective thermal management, c) robustness design and validation with the knowledge of mission profiles [9], [10], [37], [41]. This consideration should be taken into during the design and operation of a RES. It also leads to possible activities for reliability analysis and improvement as it is illustrated in Fig. 15.

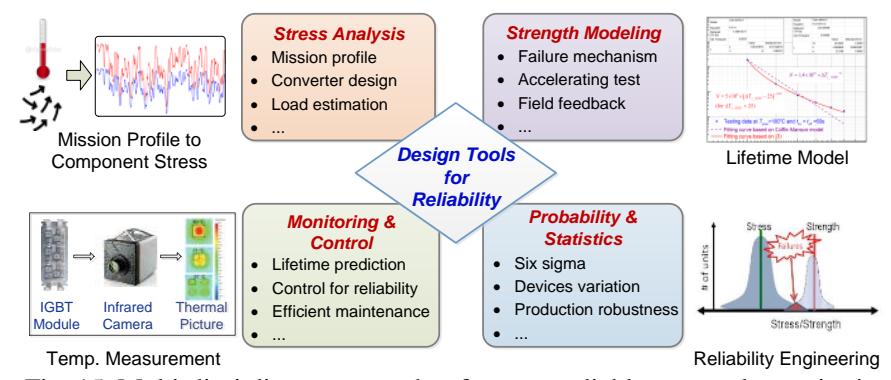

Fig. 15. Multi-disciplinary approaches for more reliable power electronics in renewable energy systems.

\section{CONCLUSIONS}

In this paper, the status and future of the key technology for renewable energy systems - power electronics have been discussed. Currently, underpinned by the power electronics technology, the electrical power generation from renewable energy sources is continuously booming in many countries. An overview of the mainstream power converter topologies for a few $\mathrm{kW}$ residential PV applications and for several MW WTSs has also been given, together with basic operation principles and control strategies. It can be concluded that the power electronics technology is playing an important role in the electricity generation, and also it will play an even more active role for both wind energy and PV applications. In the future, it is expected that there will be more advanced power electronics systems associated with intelligent control strategies for the renewable energy systems in order to increase the power capacity. Moreover, high efficiency and high reliability of the power conversion systems will be further strengthened on the purpose to reduce the cost of energy and also to extend the service period.

\section{REFERENCES}

[1] REN21, "Renewables 2013: Global Status Report (GSR)," [Online]. Available: http://www.ren21.net/, Jun. 2013.

[2] REN21, "Global Futures Report (GFR) - Scenario Profiles Report (Draft)," [Online]. Available: http://www.ren21.net/, Jan. 2013.

[3] E. J. Coster, J. M. A. Myrzik, B. Kruimer, and W. L. Kling, "Integration issues of distributed generation in distribution grids," Proc. IEEE, vol. 99, no. 1, pp. 28-39, Jan. 2011.

[4] R. Teodorescu, M. Liserre, and P. Rodriguez, Grid Converters for Photovoltaic and Wind Power Systems. Hoboken, NJ, USA: Wiley, 2011.

[5] F. Blaabjerg, R. Teodorescu, M. Liserre, and A.V. Timbus, "Overview of control and grid synchronization for distributed power generation systems," IEEE Trans. Ind. Electron., vol. 53, no. 5, pp. 1398-1409, Oct. 2006.
[6] S.B. Kjaer, J.K. Pedersen, and F. Blaabjerg, "A review of single-phase grid-connected inverters for photovoltaic modules," IEEE Trans. Ind. Appl., vol. 41, no. 5, pp. 1292-1306, Sept.-Oct. 2005.

[7] D. Meneses, F. Blaabjerg, O. García, and J.A. Cobos, "Review and comparison of step-up transformerless topologies for photovoltaic ACmodule application," IEEE Trans. Power Electron., vol. 28, no. 6, pp. 2649-2663, Jun. 2013.

[8] F. Blaabjerg, Z. Chen, and S.B. Kjaer, "Power electronics as efficient interface in dispersed power generation systems," IEEE Trans. Power Electron., vol. 19, no. 5, pp. 1184-1194, Sept. 2004.

[9] F. Blaabjerg, M. Liserre, and K. Ma, "Power electronics converters for wind turbine systems," IEEE Trans. Ind. Appl., vol. 48, no. 2, pp. 708719, Mar.-Apr. 2012.

[10] F. Blaabjerg and K. Ma, "Future on power electronics for wind turbine systems," IEEE Journal of Emerging and Selected Topics in Power Electronics, in press, 2013.

[11] J.M. Carrasco, L.G. Franquelo, J.T. Bialasiewicz, E. Galvan, R.C.P. Guisado, Ma.A.M. Prats, J.I. Leon, and N. Moreno-Alfonso, "Powerelectronic systems for the grid integration of renewable energy sources: a survey," IEEE Trans. Ind. Electron., vol. 53, no. 4, pp. 1002-1016, Jun. 2006.

[12] M. Liserre, T. Sauter, and J.Y. Hung, "Future energy systems: Integrating renewable energy sources into the smart power grid through industrial electronics," IEEE Ind. Electron. Mag., vol. 4, no. 1, pp. 18-37, Mar. 2010.

[13] M. Liserre, R. Cardenas, M. Molinas, and J. Rodriguez, "Overview of multi-MW wind turbines and wind parks," IEEE Trans. Ind. Electron., vol. 58, no. 4, pp. 1081-1095, Apr. 2011.

[14] K. Ma and F. Blaabjerg, "Multilevel converters for $10 \mathrm{MW}$ wind turbines," in Proc. of EPE'11, pp. 1-10, Aug. 30 2011-Sept. 12011.

[15] J. Rodriguez, S. Bernet, P.K. Steimer, and I.E. Lizama, "A survey on neutral-point-clamped inverters," IEEE Trans. Ind. Electron., vol. 57, no. 7, pp. 2219-2230, Jul. 2010.

[16] F. Blaabjerg, K. Ma, and D. Zhou, "Power electronics and reliability in renewable energy systems," in Proc. of ISIE, pp. 19-30, 28-31 May 2012.

[17] B. Andresen and J. Birk, "A high power density converter system for the Gamesa G10x 4.5 MW Wind turbine," in Proc. of EPE, pp. 1-7, 2007.

[18] R. Jones and P. Waite, "Optimised power converter for multi-MW direct drive permanent magnet wind turbines, " in Proc. of EPE, pp. 1-10, 2011.

[19] S.V. Araujo, P. Zacharias, and R. Mallwitz, "Highly efficient singlephase transformerless inverters for grid-connected PV systems," IEEE Trans. Ind. Electron., vol. 57, no. 9, pp. 3118-3128, Sept. 2010.

[20] R. Gonzalez, J. Lopez, P. Sanchis, and L. Marroyo, "Transformerless inverter for single-phase photovoltaic systems," IEEE Trans. Power Electron., vol. 22, no. 2, pp. 693-697, Mar. 2007.

[21] T. Kerekes, R. Teodorescu, P. Rodriguez, G. Vazquez, and E. Aldabas, "A new high-efficiency single-phase transformerless PV inverter topology," IEEE Trans. Ind. Electron., vol. 58, no. 1, pp. 184-191, Jan. 2011.

[22] H. Schmidt, S. Christoph, and J. Ketterer, "Current inverter for direct/alternating currents, has direct and alternating connections with an intermediate power store, a bridge circuit, rectifier diodes and a inductive choke," German Patent DE10 221592 A1, 4 Dec. 2003.

[23] I. Patrao, E. Figueres, F. Gonzalez-Espin, and G. Garcera, "Transformerless topologies for grid-connected single-phase photovoltaic inverters," Renewable and Sustainable Energy Reviews, vol. 15, no. 7, pp. 34233431, Sept. 2011.

[24] L. Zhang, K. Sun, L. Feng, H. Wu, and Y. Xing, "A family of neutral point clamped full-bridge topologies for transformerless photovoltaic grid-tied inverters," IEEE Trans. Power Electron., vol. 28, no. 2, pp. 730-739, Feb. 2013.

[25] B. Gu, J. Dominic, J.-S. Lai, C.-L. Chen, T. LaBella, and B. Chen, "High reliability and efficiency single-phase transformerless inverter for gridconnected photovoltaic systems," IEEE Trans. Power Electron., vol. 28, no. 5, pp. 2235-2245, May 2013

[26] E. ON GmbH, "Grid Code - High and extra high voltage." [Online]. Available: http://www.eon-netz.com/. 
[27] Comitato Elettrotecnico Italiano, "CEI 0-21: Reference technical rules for connecting users to the active and passive LV distribution companies of electricity." [Online]. Available: http://www.ceiweb.it/.

[28] P. Rodriguez, A.V. Timbus, R. Teodorescu, M. Liserre, and F. Blaabjerg, "Flexible active power control of distributed power generation systems during grid faults," IEEE Trans. Ind. Electron., vol. 54, no. 5, pp. 2583-2592, Oct. 2007.

[29] G.M.S. Azevedo, G. Vazquez, A. Luna, D. Aguilar, and A. Rolan, "Photovoltaic inverters with fault ride-through Capability," in Proc. of ISIE'09, pp. 549-553, 5-8 Jul. 2009.

[30] C.H. Benz, W.-T. Franke, and F.W. Fuchs, "Low voltage ride through capability of a $5 \mathrm{~kW}$ grid-tied solar inverter," in Proc. of EPE/PEMC, pp. T12-13-T12-20, 6-8 Sept. 2010.

[31] X. Bao, P. Tan, F. Zhuo, and X. Yue, "Low voltage ride through control strategy for high-power grid-connected photovoltaic inverter," in Proc. of APEC'13, pp. 97-100, 17-21 Mar. 2013.

[32] H.-C. Chen, C.-T. Lee, P.T. Cheng, R.Teodorescu, F. Blaabjerg, and S. Bhattacharya, "A flexible low-voltage ride-through operation for the distributed generation converters," in Proc. of PEDS'13, pp. 1354-1359, 22-25 Apr. 2013.

[33] N.P. Papanikolaou, "Low-voltage ride-through concept in flyback inverterbased alternating current photovoltaic modules," IET Power Electron., vol. 6, no. 7, pp. 1436-1448, Aug. 2013.

[34] Y. Bae, T.-K. Vu, and R.-Y. Kim, "Implemental control strategy for grid stabilization of grid-connected PV system based on german grid code in symmetrical low-to-medium voltage network," IEEE Trans. Energy Conv., vol. 28, no. 3, pp. 619-631, Sept. 2013.
[35] Y. Yang, F. Blaabjerg, and Z. Zou, "Benchmarking of grid fault modes in single-phase grid-connected photovoltaic systems," IEEE Trans. Ind. Appl., vol. 49, no. 5, in press, Sept./Oct. 2013.

[36] Y. Yang, F. Blaabjerg, and H. Wang, "Low voltage ride-through of single-phase transformerless photovoltaic inverters," in Proc. of ECCE'13, Sept. 2013.

[37] H. Wang, M. Liserre, and F. Blaabjerg, "Toward reliable power electronics: challenges, design tools, and opportunities," IEEE Ind. Electron. Mag., vol. 7, no. 2, pp. 17-26, Jun. 2013.

[38] J.D., van Wyk and F.C. Lee, "On a future for power electronics," IEEE Journal of Emerging and Selected Topics in Power Electronics, , vol. 1, no. 2, pp. 59-72, Jun. 2013.

[39] J.G. Kassakian and T.M. Jahns, "Evolving and emerging applications of power electronics in systems," IEEE Journal of Emerging and Selected Topics in Power Electronics, vol. 1, no. 2, pp. 47-58, Jun. 2013.

[40] M. Campbell, J. Blunden, E. Smeloff, and P. Aschenbrenner, "Minimizing utility-scale PV power plant LCOE through the use of high capacity factor configurations," in Proc. of IEEE PVSC, pp. 421-426, 712 Jun. 2009.

[41] E. Koutroulis and F. Blaabjerg, "Design optimization of transformerless grid-connected PV inverters including reliability," IEEE Trans. Power Electron., vol. 28, no. 1, pp. 325-335, Jan. 2013.

[42] U.S. Energy Information Administration, "Levelized Cost of New Generation Resources in the Annual Energy Outlook 2013, " [Online] Tech. Rep., Jan. 2013. Available: http://www.eia.gov/. 